\title{
A table avec Wagner !
}

\section{Daniel Bornemann}

\section{(2) OpenEdition}

\author{
Journals
}

Édition électronique

URL : https://journals.openedition.org/rbnu/2357

DOI : $10.4000 /$ rbnu.2357

ISSN : 2679-6104

\section{Éditeur}

Bibliothèque nationale et universitaire de Strasbourg

\section{Édition imprimée}

Date de publication : 1 mai 2013

Pagination : 74-85

ISBN : 9782859230432

ISSN : 2109-2761

\section{Référence électronique}

Daniel Bornemann, «A table avec Wagner ! », La Revue de la BNU [En ligne], 7 | 2013, mis en ligne le 01 mai 2013, consulté le 09 août 2021. URL : http://journals.openedition.org/rbnu/2357 ; DOI : https:// doi.org/10.4000/rbnu. 2357

\section{(C) $10(0$}

La Revue de la BNU est mise à disposition selon les termes de la Licence Creative Commons Attribution - Pas d'Utilisation Commerciale - Partage dans les Mêmes Conditions 4.0 International. 
+ PORTFOLIO

\section{A table avec Wagner!}


Vers l'année 1900, les faïenceries de Sarreguemines mirent sur le marché une suite de douze assiettes décorées de motifs wagnériens : des scènes identifiables de presque tous les opéras y sont représentées par au moins une assiette, et chacune porte également en médaillon un portrait noir et blanc de Richard Wagner. Dans cette série, chaque assiette a un titre : celui d'un opéra de Wagner, écrit en langue allemande mais en écriture romaine, et chacune comporte également quelques portées de la partie de chant qui correspond à la scène représentée, avec éventuellement une mention précise de la scène et de l'acte, ou du nom du personnage qui doit chanter le texte, en écriture ronde. Une couronne de laurier et de houx entoure l'assiette, entre deux liserés bleus.

Le portrait de Richard Wagner n'est pas des plus communs. C'est un profil gauche de l'artiste, vraisemblablement issu d'un cliché signé Elliott \& Fry, compagnie photographique anglaise. Ce cliché a également été gravé par la firme Augener et Compagnie, un éditeur de musique londonien. Aucune signature d'artiste ou de graveur n'apparaît sur les assiettes ellesmêmes, ni pour le portrait, ni pour les scènes d'opéras. L'omniprésence de ce portrait de Wagner montre bien l'importance accordée à la personnalité de l'artiste, autant qu'à ses œuvres lyriques. Cette personnalisation semble propre à la musique dans l'esprit des créateurs d'assiettes décoratives à Sarreguemines : une série d'assiettes consacrées à des opérettes du temps, fabriquée au même endroit, montre également des notes de musique autour de scènes d'œuvres, et les portraits de deux auteurs sont reproduits en médaillon : Franz von Suppé pour Fatiniza et Gaston Serpette pour Le Petit chaperon rouge. Pour des œuvres littéraires par contre, les portraits des auteurs ne sont pas reproduits (Erckmann-Chatrian ou Gustave Stoskopf par exemple).

Les motifs des assiettes consacrées à Wagner montrent les personnages principaux des drames, dans des décors dont le style peut être qualifié d'historiciste, et dans des tonalités claires. Sont-ce des productions graphiques issues de mises en scène réelles ? Si oui, elles sont dans le style de l'opéra romantique, et non symboliste. La couronne végétale qui fait le tour de la scène semble être posée sur l'assiette plus que peinte, car les ombres qu'elle engendre sont reportées sur les bordures. Elle donne du relief aux assiettes, contrairement aux scènes d'opéras auxquelles on pourrait reprocher leur pâleur, leur manque de vigueur.

La marque qui apparaît au dos des assiettes a été employée de 1860 à 1920. Elle est composée du nom Sarreguemines en écriture cursive surchargée des lettres $\mathrm{U} \& \mathrm{C}$, pour Utzschneider et Compagnie. Les lettres et

chiffres poinçonnés sur le fond des assiettes désignent les ouvriers du façonnage (calibreurs ou mouleurs) qui ont travaillé sur ce produit. Sur cette série, on peut relever $2 \mathrm{M}, 2 \mathrm{H}, 2 \mathrm{P}$, par exemple. Des griffes et signes de contrôle peints apparaissent également : chiffres, lettres et tirets difficiles à interpréter, mais qui laissent soupçonner un contrôle de la qualité poussé à tous les stades de la fabrication.

La forme de ces assiettes est appelée "lentille", autrement dit sans bassin ni marli (rebord) ; elle est uniquement formée d'une coupe de forme régulière. Le diamètre des assiettes est de $22 \mathrm{~cm}$, leur hauteur est de $2,4 \mathrm{~cm}$. Elles sont munies de deux trous dans le talon, qui permettent leur accrochage mural.

Cette forme " lentille » a été également utilisée pour la série D'r Herr Maire d'après la pièce de G. Stoskopf, dont les motifs furent créés par le peintre Regamey, ainsi que pour d'autres séries reposant sur des succès littéraires ou artistiques populaires, destinées à la décoration intérieure. La technique de report de l'image, dite transfert d'impression, permit en effet la popularisation des séries illustrées à partir de 1830 . Cette technique à base de lithographie fut en usage jusqu'en 1965 environ, date à laquelle elle fut remplacée par un procédé à base de sérigraphie.

Tout comme l'œuvre de Wagner, les faïenceries de Sarreguemines eurent elles aussi un destin francoallemand. En 1870, la Moselle est annexée à l'Empire allemand et la société est scindée en plusieurs entités dépendantes les unes des autres, basées de part et d'autre de la nouvelle frontière. Les implantations de Digoin et de Vitry-le-François, ainsi que des ateliers plus petits installés autour de Paris, firent vivre l'industrie du côté français, et accueillirent nombre d'ouvriers " optants". Durant cette période de l'annexion, les faienceries de Sarreguemines devinrent l'une des plus grandes entreprises céramiques mondiales.

Les produits de ce site industriel étaient d'ailleurs destinés tant à la France qu'à l'Allemagne. Cette série wagnérienne eut-elle plus de succès d'un côté que de l'autre des nouvelles frontières ? Nous ne saurions donner de réponse là-dessus.

Les assiettes présentées ici font toutes partie du fonds Boulet-Devraigne.

\section{Daniel Bornemann}




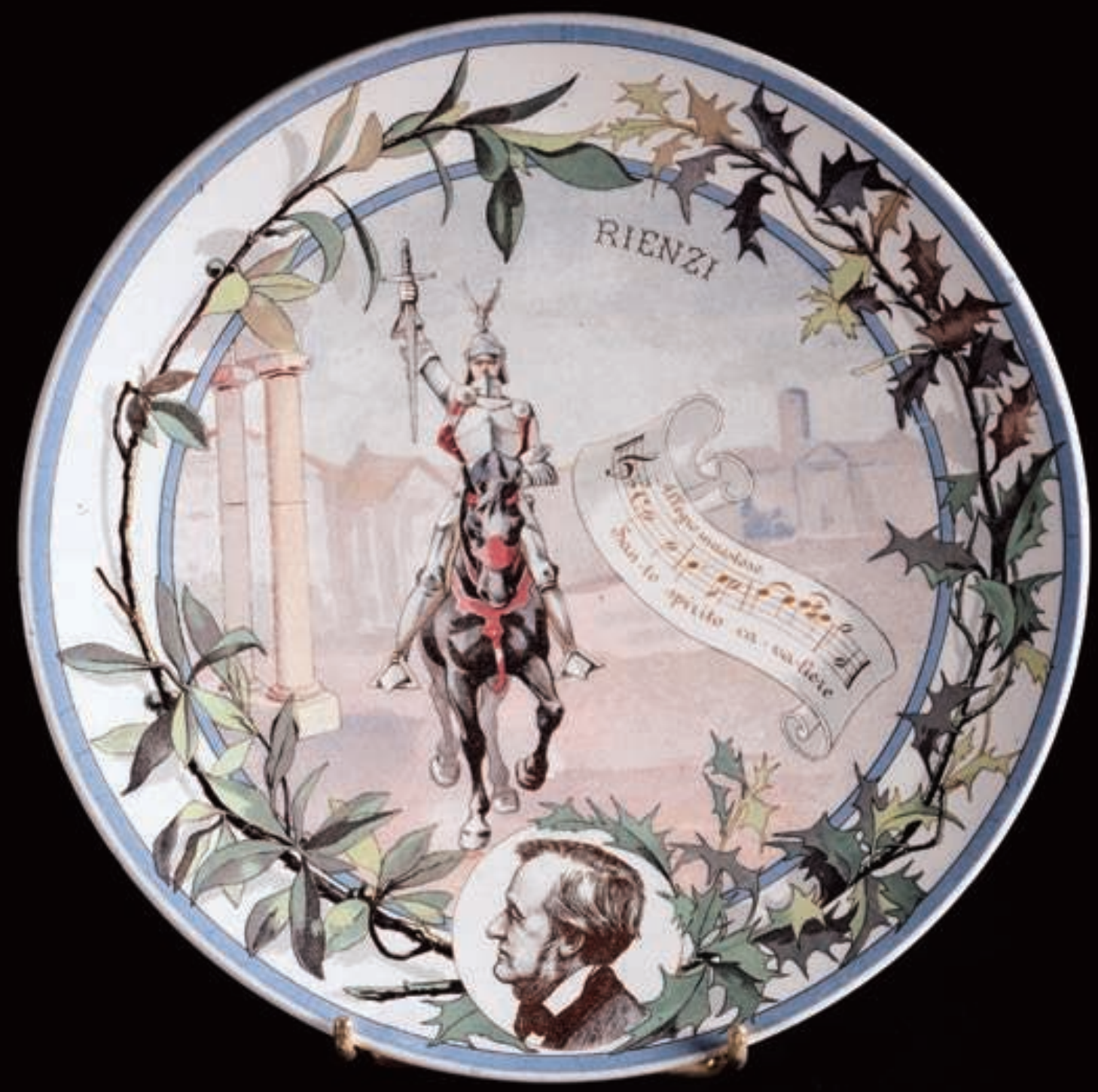




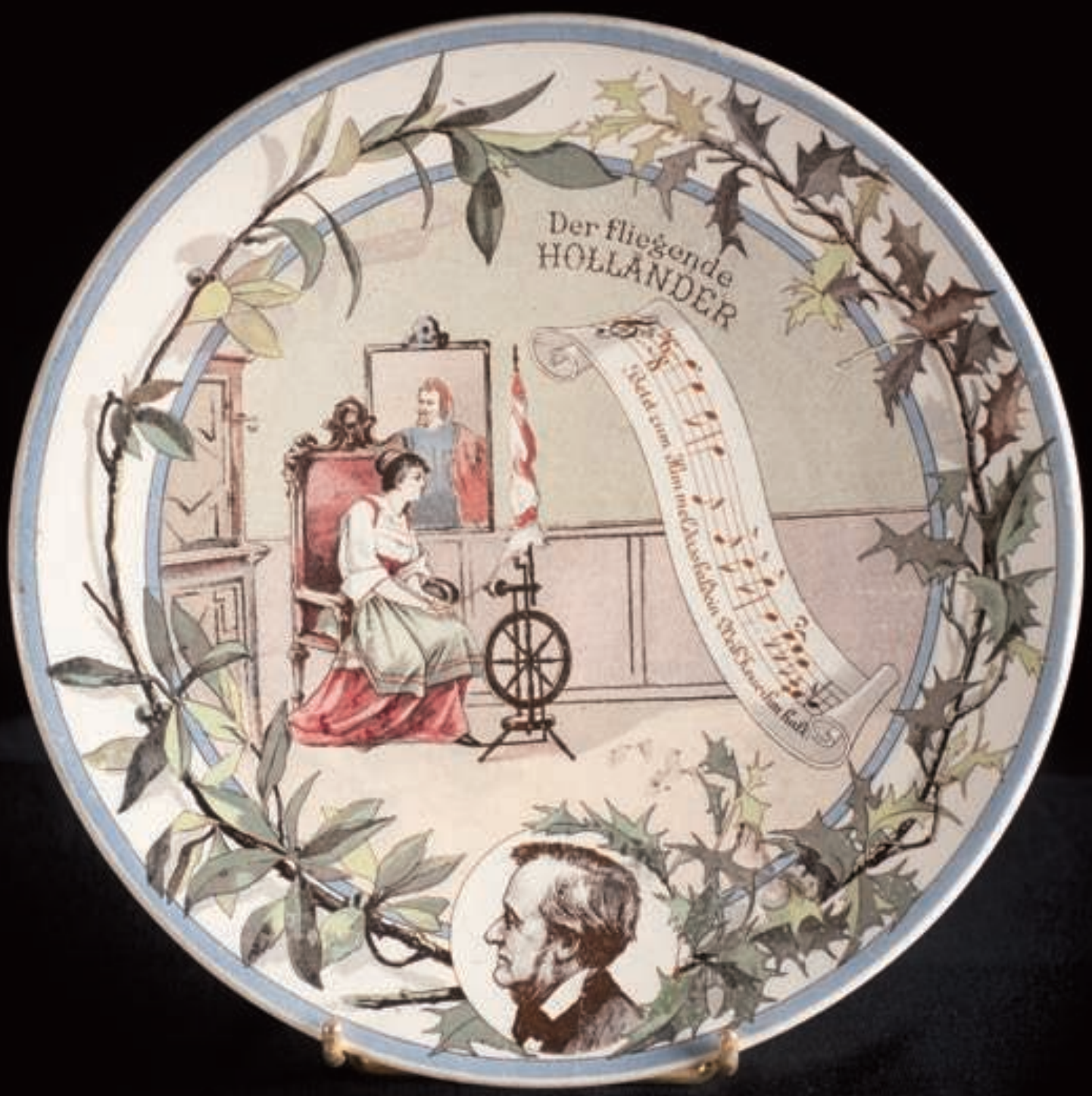




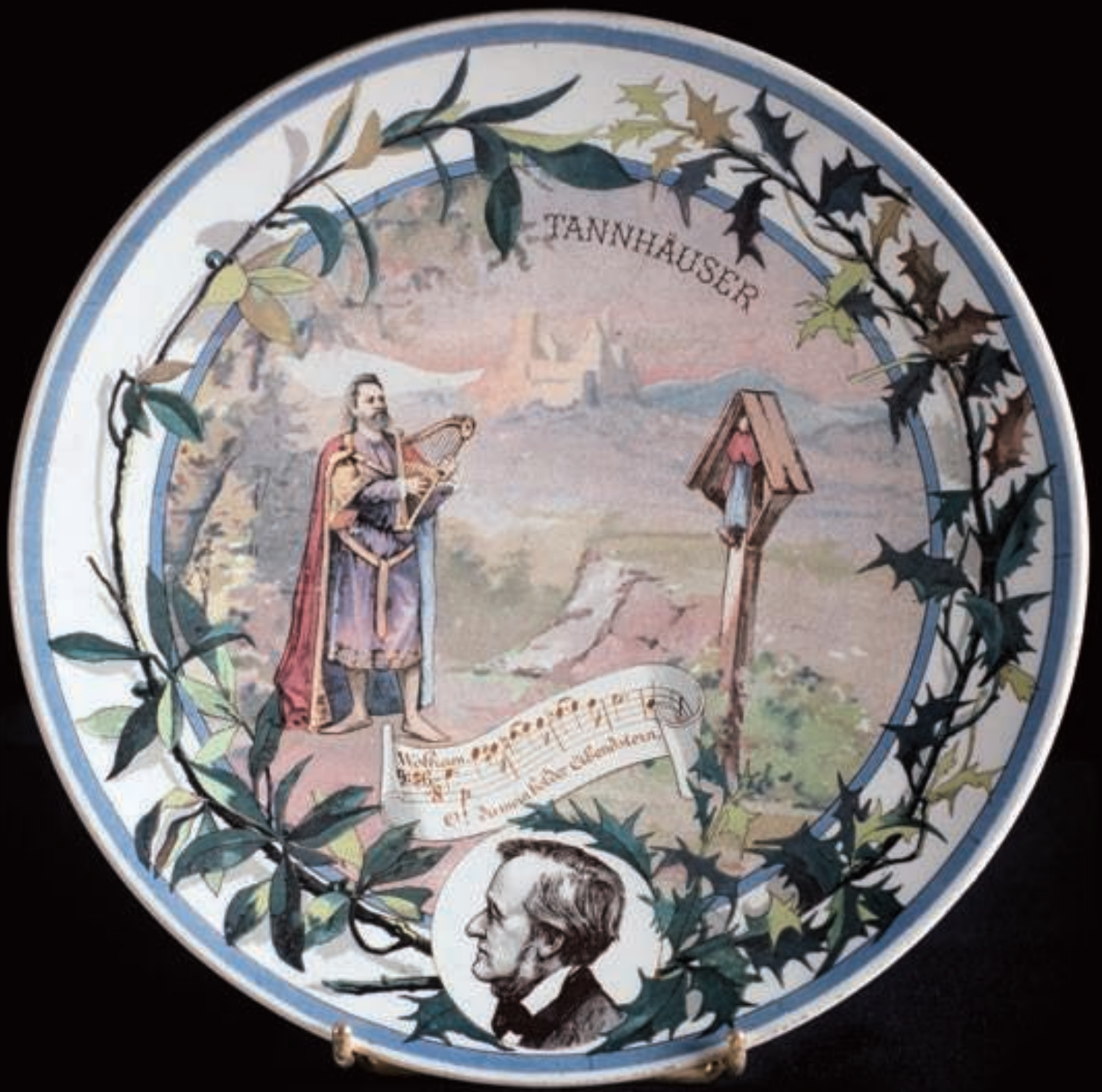




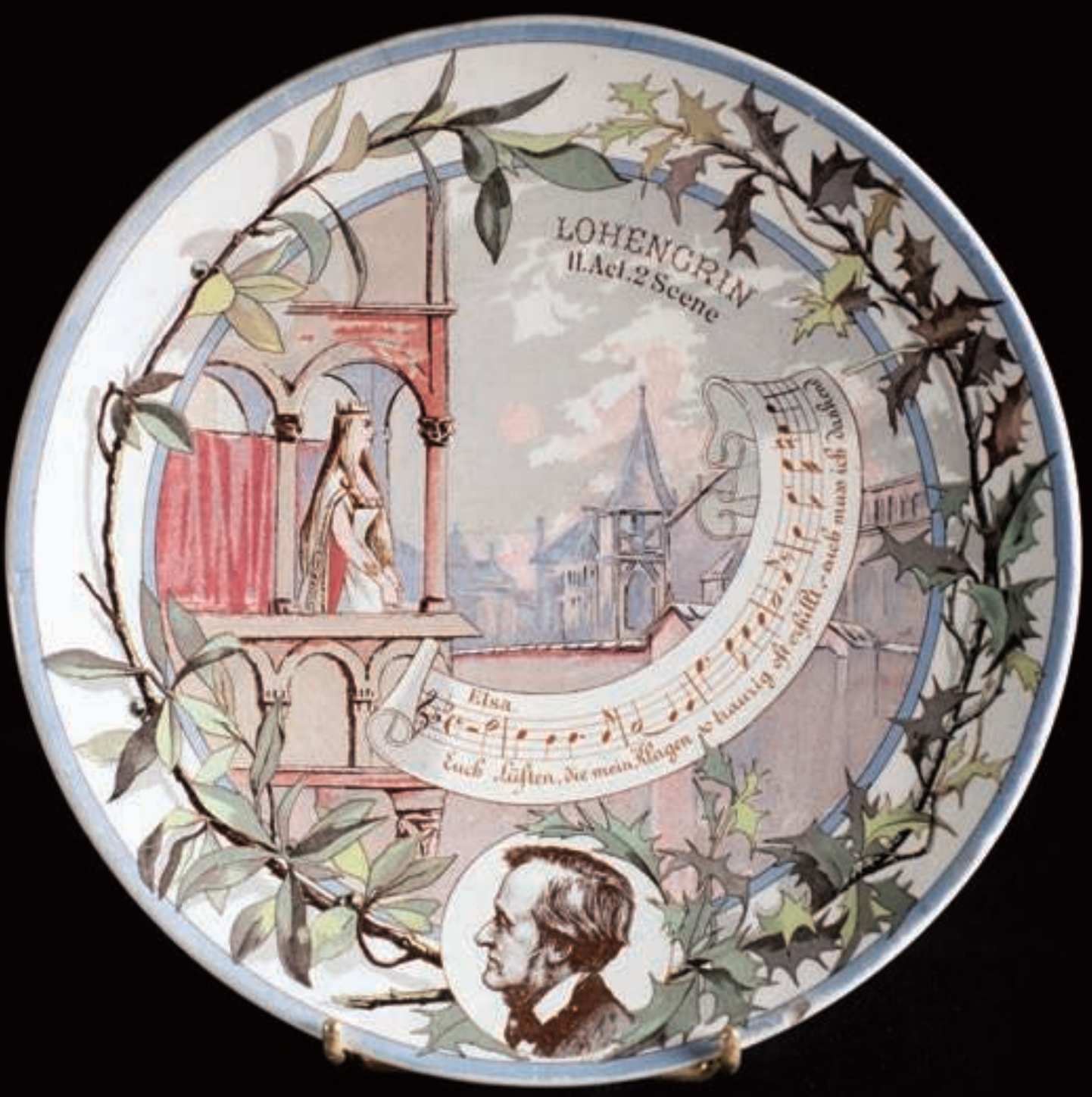




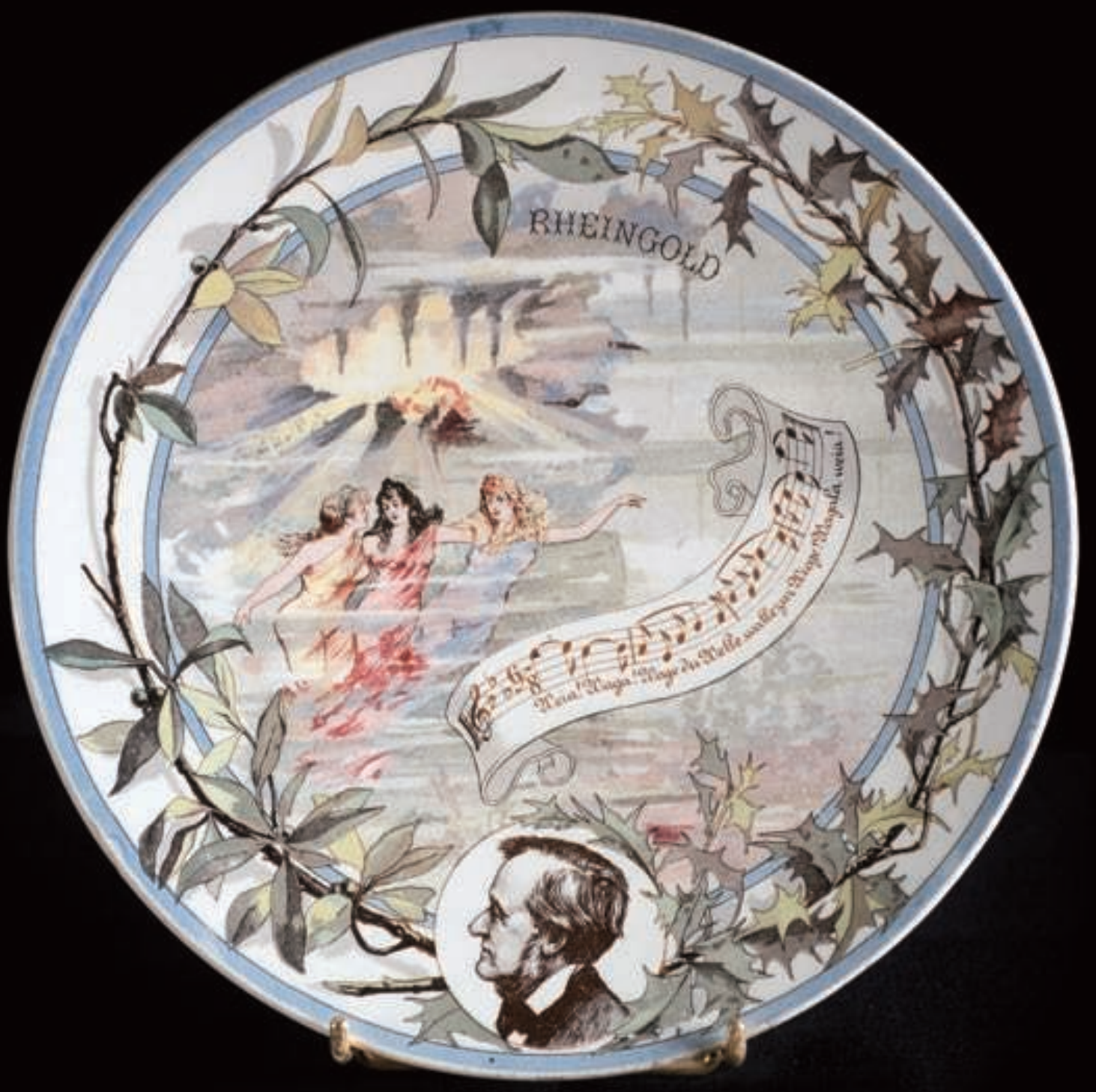




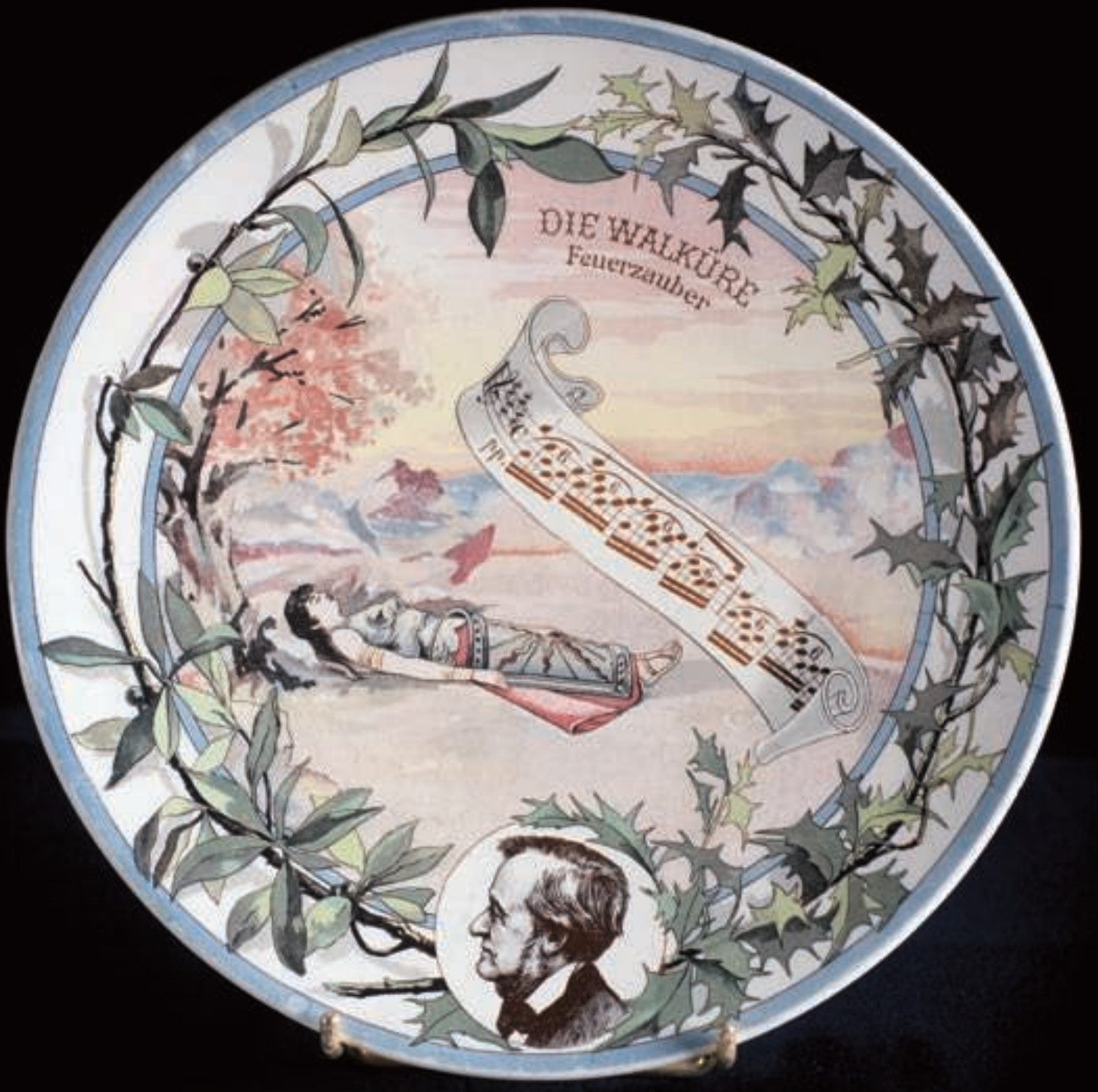




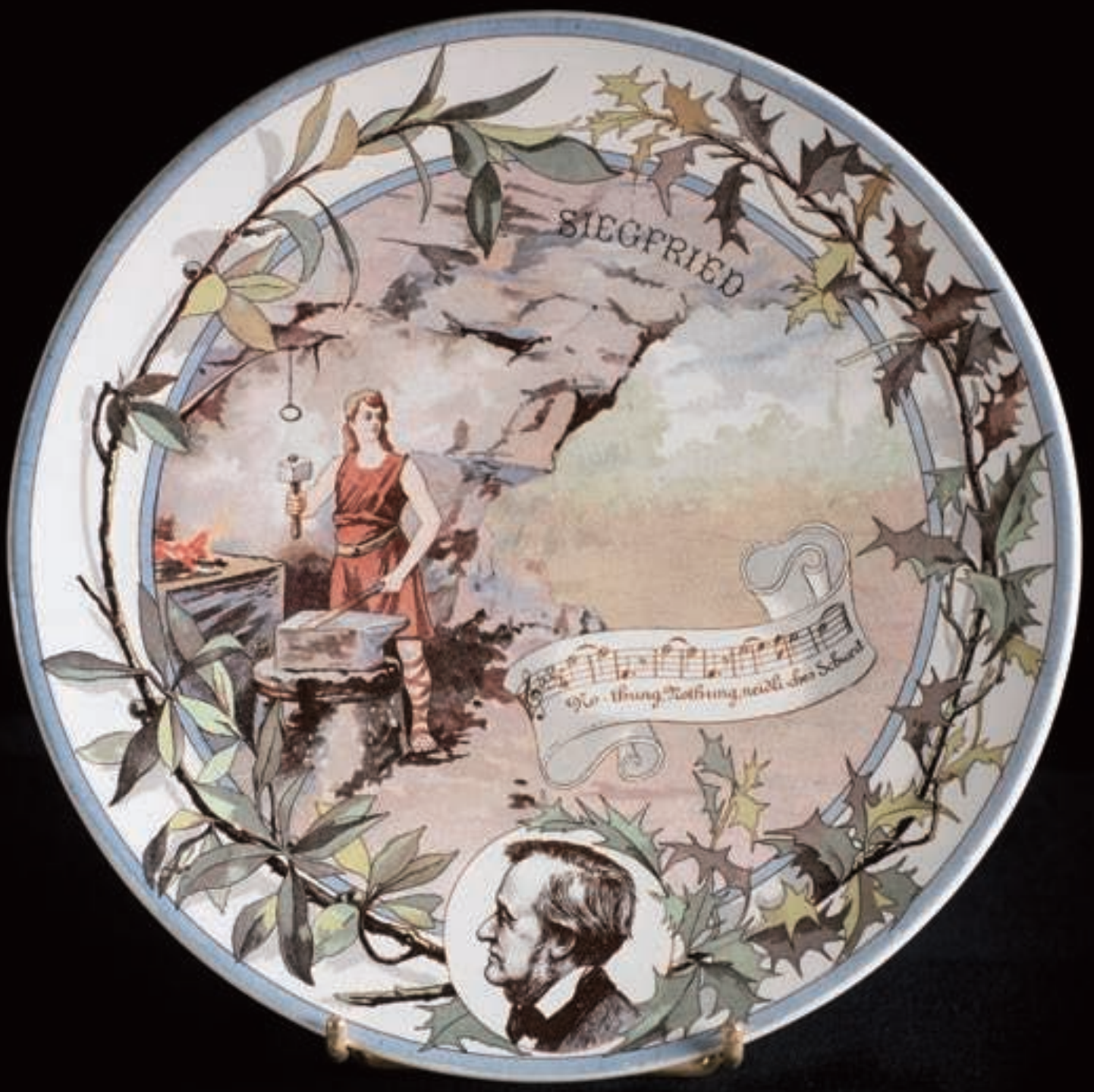




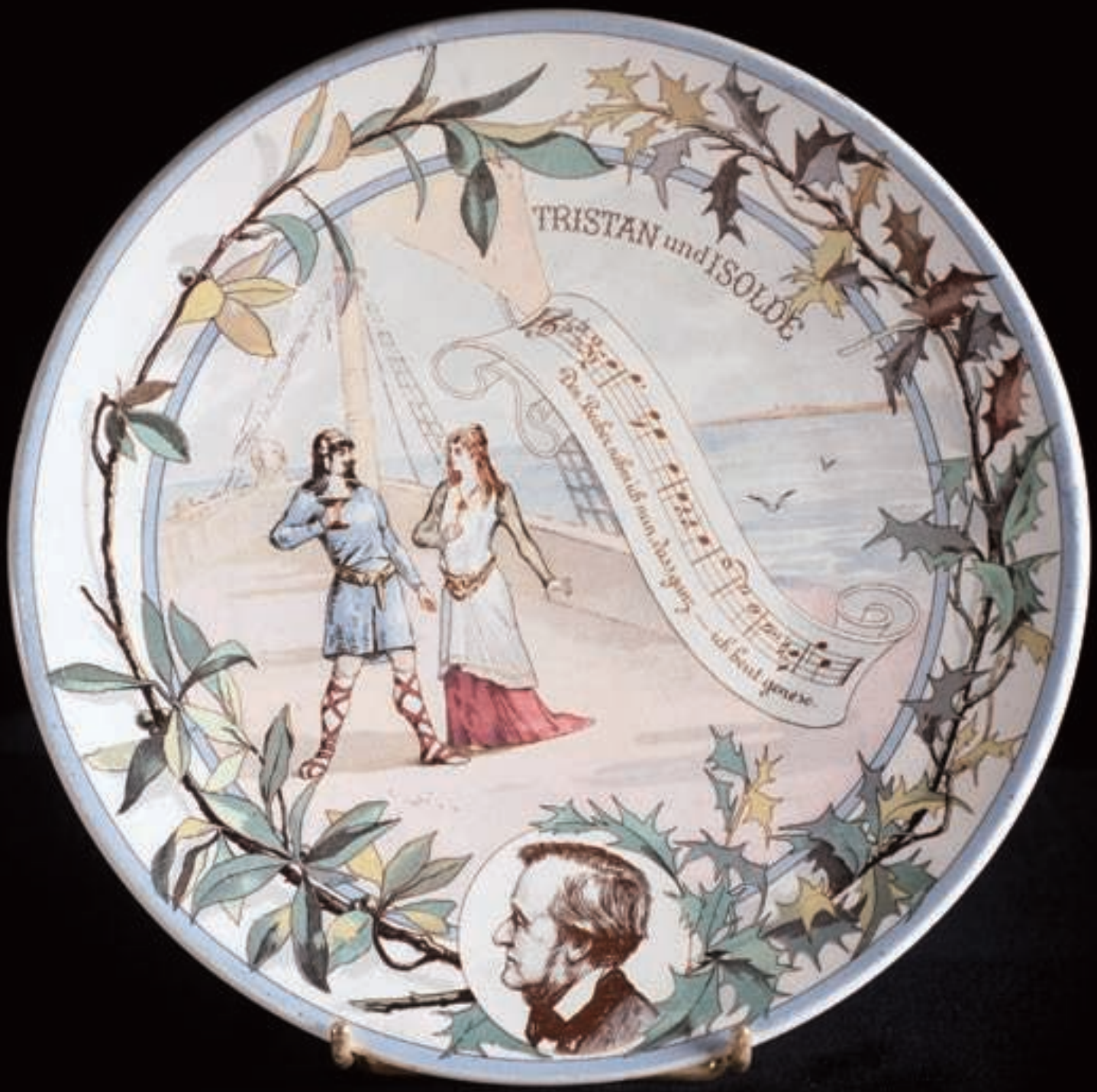




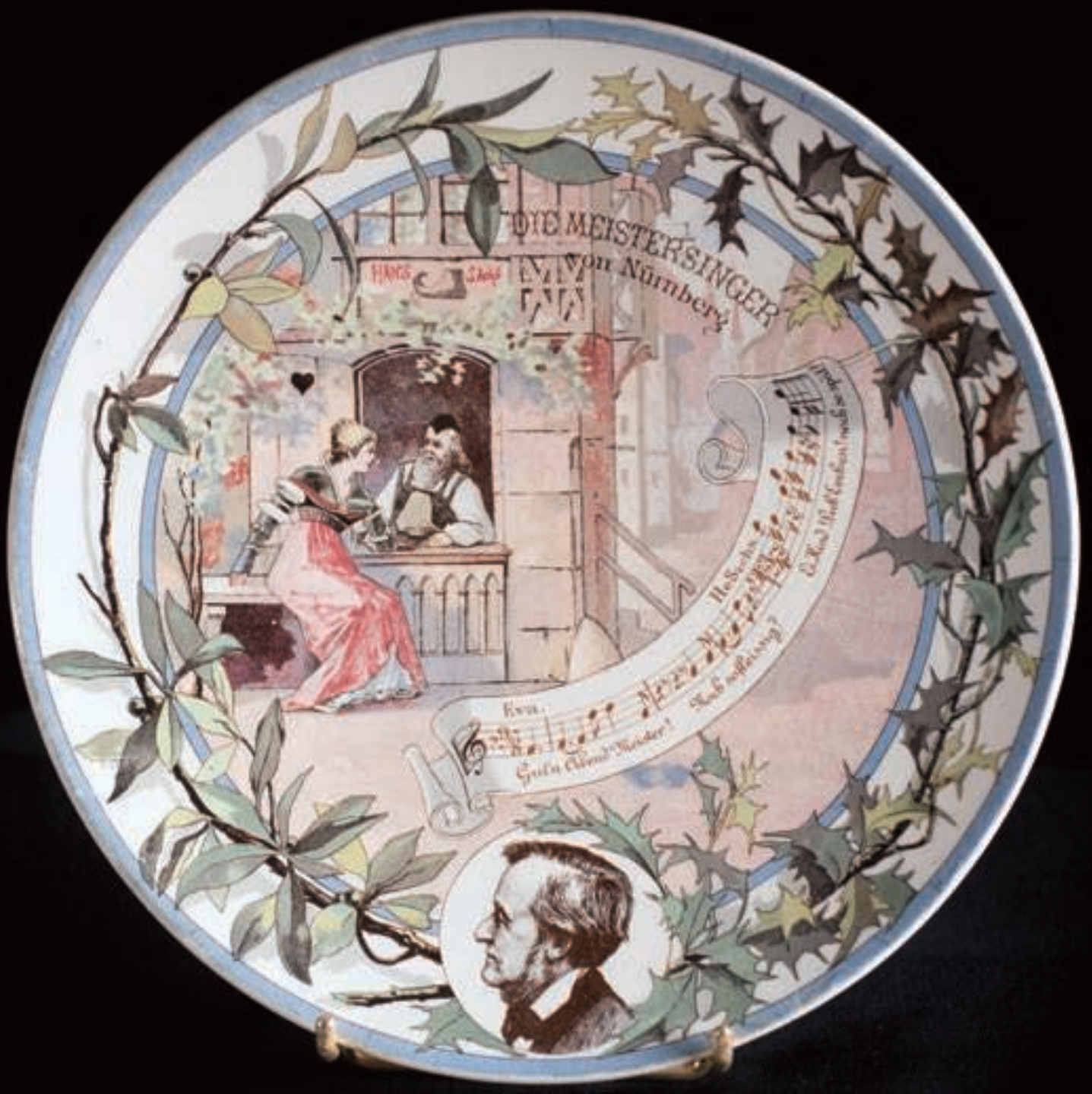




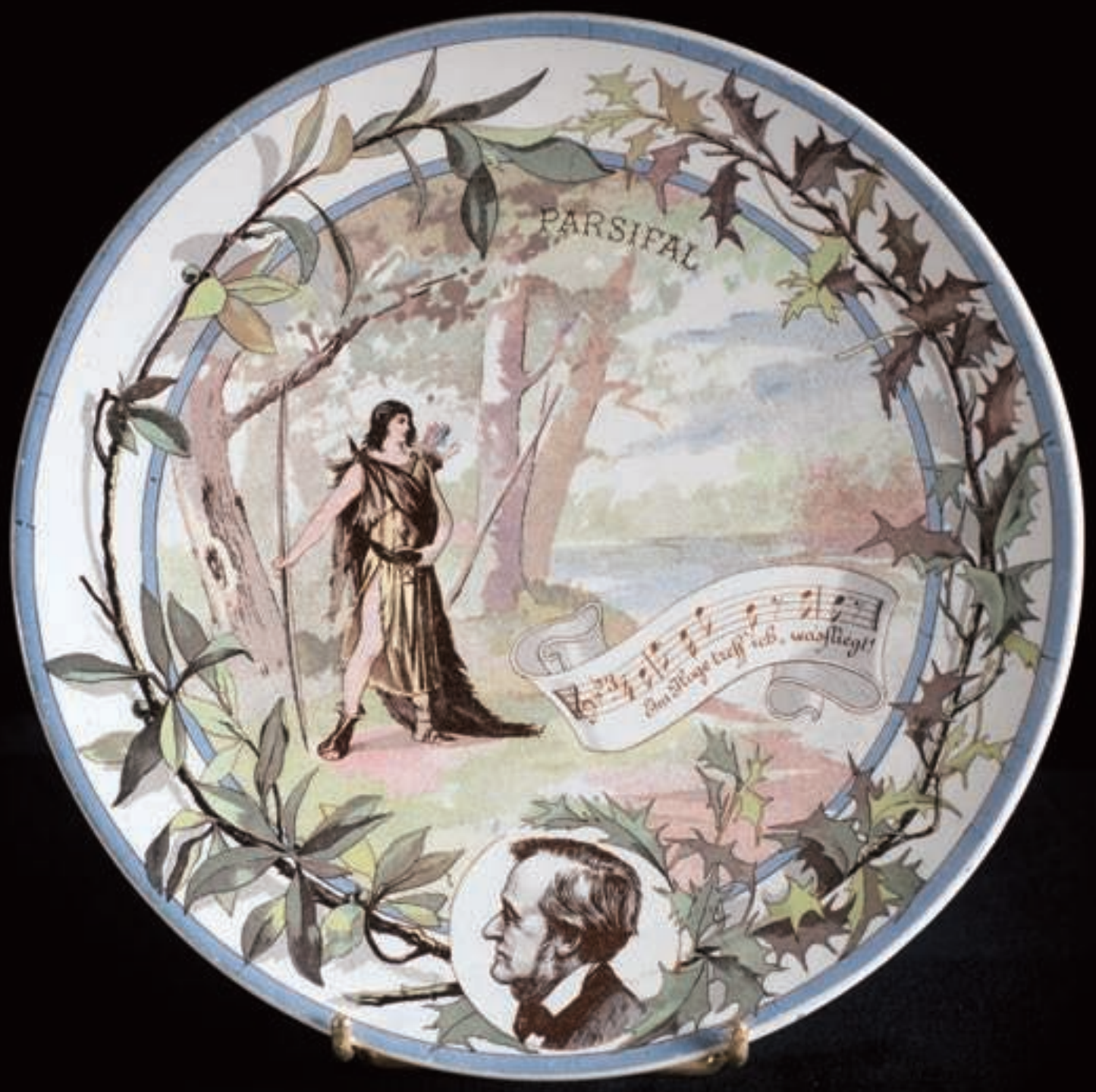

